\title{
IMPACTOS DO TELETRABALHO NA SAÚDE MENTAL DO TRABALHADOR: UMA REVISÃO DE LITERATURA
}

\author{
Thailini Vebber ${ }^{1}$, Silvana Maia Borges²
}

RESUMO: 0 teletrabalho refere-se à atividade laboral realizada remotamente, utilizando computadores, celulares e dispositivos de comunicação. 0 teletrabalho é uma forma de atuação ainda pouco convencional, que contém vantagens e também dificuldades inerentes. Considerando o exposto, o objetivo desta pesquisa foi identificar os impactos causados pelo teletrabalho na saúde mental dos trabalhadores, apontando os principais riscos e benefícios que ele pode oferecer. A pesquisa é de abordagem qualitativa e constituiu-se em uma revisão narrativa de literatura. A busca de materiais ocorreu nas bases de dados PePSCI, SCIELO, LILACS e no buscador Google Acadêmico. A análise dos dados se deu por meio da análise de conteúdo e os resultados e discussões foram divididos em três categorias, sendo elas: Impactos da Pandemia: mudanças na rotina de quem passou a atuar no teletrabalho; Vantagens e desvantagens do Teletrabalho sob diferentes perspectivas; Efeitos do teletrabalho na saúde mental e estratégias de enfrentamento dos seus riscos. Os resultados apontaram impactos na rotina de quem migrou para o teletrabalho no período pandêmico, onde os conflitos nas relações familiares e domésticas se intensificaram. Foi possível verificar também as vantagens e desvantagens do teletrabalho, sendo que as desvantagens se mostram prevalentes, podendo gerar danos à saúde mental dos teletrabalhadores. Concluiu-se que o teletrabalho pode trazer impactos à saúde mental dos trabalhadores, e que tanto a psicologia quanto as organizações ainda precisam se aprofundar para poder compreender e intervir nesses impactos.

Palavras-chave: Efeitos do teletrabalho; Home office; Saúde do trabalhador; Trabalho na pandemia.

Submissão: 16/11/2021

Aceite: 03/01/2021

DOI: 10.47591/RAC.2674-9203.2021v3n2.art1-1-17

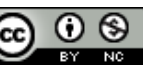

Este trabalho está licenciado com uma Licença Creative Commons Atribuição-NãoComercial 4.0 Internacional.

\footnotetext{
${ }^{1}$ Psicóloga pela Faculdade Integrada de Santa Maria - FISMA. E-mail: thailini.vebber@fisma.com.br.

${ }^{2}$ Psicóloga pela Universidade Franciscana (graduação), Mestra em Educação pela Universidade Federal da Fronteira Sul, e atualmente docente da Faculdade Integrada de Santa Maria - FISMA. E-mail: silvana.borges@fisma.com.br.
} 
O teletrabalho, de modo geral, é uma forma de atuação ainda pouco convencional, que contém vantagens e também dificuldades inerentes, sendo necessário, portanto, considerar os fatores que influenciam na saúde física e mental de quem trabalha nessa modalidade. Isso leva a atentar aos aspectos ergonômicos, fisiológicos, sociais e psicológicos que impactam no desempenho, na produtividade, na realização profissional e na saúde global dos indivíduos que atuam através do teletrabalho. Segundo Nilles (1997), o teletrabalho é uma modalidade inserida no contexto das novas formas de trabalho, o qual facilita a realização das atividades laborais fora do ambiente comum organizacional. A realização das tarefas nesta modalidade ocorre, assim, por meio do uso de tecnologias digitais da informação e comunicação (TDICs).

De acordo com Mello e Ferreira (2014), o teletrabalho não é novidade em muitos países. Há aproximadamente três décadas estudos são realizados sobre esse tema, embora no Brasil as pesquisas sejam mais recentes. Além disso, sabe-se que o trabalho influencia todos os aspectos da vida do indivíduo, tendo um papel ativo na construção da identidade do sujeito e da vida em sociedade (MALVEZZI, 2004). Agregado a isso, o autor traz que o teletrabalho se encontra como via potencial de sofrimento, seja de forma objetiva ou subjetiva.

Cabe destacar que a pandemia da COVID-191 tornou o teletrabalho necessário e visível em todo o mundo, gerando mudanças significativas no cenário laboral, pois as medidas de distanciamento social, decorrentes da crise gerada pela emergência em saúde, estimularam a ampliação do teletrabalho. Em 11 de março de 2020, a Organização Mundial da Saúde (OMS) declarou a pandemia da COVID-19, dando início ao que talvez venha a ser considerado um novo período histórico (SCHMIDT et al., 2020). As orientações de distanciamento social, quarentena ${ }^{2}$, trancamentos de fronteiras e interrupções de serviços presenciais não essenciais, para controle do vírus, foram implementados, reduzindo fortemente a mobilidade das pessoas. Os comportamentos sociais em diferentes esferas da vida, como família, amizade, religião e trabalho passaram a ser, com muito mais frequência, mediados pela tecnologia digital. Logo, a pandemia trouxe mudanças bruscas na vida das pessoas e em suas rotinas de trabalho, sobretudo para aqueles que passaram a realizar o teletrabalho de forma compulsória.

Além do referido, a pandemia provocou muitos sentimentos, como o medo, insegurança, solidão, incerteza, ansiedade, sofrimento pelas perdas, luto, estresse, dentre outros. Esses estados afetivos têm se somado aos desafios do teletrabalho compulsório, onde o trabalhador passou a lidar com os inúmeros desafios dessa nova realidade. Segundo Rodrigues, Moscon, Queiroz e Silva (2020), a prática do

\footnotetext{
1 O SARS-CoV-2, também denominado como coronavírus, causa a doença COVID-19, a qual apresenta um espectro clínico variando de infecções assintomáticas a quadros graves, com sintomas que vão de um resfriado a uma pneumonia severa. Disponível em: https://coronavirus.saude.gov.br/sobrea-doenca. Acesso em: 16 nov. 2021.

${ }^{2}$ Quarentena: restrição de atividades ou separação de pessoas que não estão doentes, mas que podem ter sido expostas ao COVID-19 (OMS, 2020). Disponível em: https://iris.paho.org/bitstream/handle/10665.2/51961/OPASBRACOVID1920023 por.pdf?sequence=1\&i sAllowed=y. Acesso em: 13 abr. 2021.
} 
teletrabalho ganhou força com a pandemia, em 2020, pois muitas empresas adotaram a prática do teletrabalho, o que exigiu dos sujeitos uma rápida adaptação ao trabalho remoto.

Entretanto, a maioria dos trabalhadores experimentou pela primeira vez o teletrabalho, sem qualquer preparação, tanto material, quanto psicológica, para essa súbita transição. Desse modo, houve uma mudança abrupta na rotina do trabalhador nesse período pandêmico, onde de uma hora para outra se adotou o teletrabalho, havendo a necessidade de aprender a trabalhar de casa e lidar com as novas variáveis contextuais, como o espaço e o tempo que se tem para realizar o trabalho. Exemplifica-se isso com a ausência de mobiliários e equipamentos adequados e a conciliação do trabalho com atividades domésticas e pessoais, sobreposições que poderão acarretar o desenvolvimento de estresse, comprometendo a saúde mental do indivíduo.

Considerando o exposto, o presente artigo buscou reunir informações para responder a seguinte problemática: como o teletrabalho impacta na saúde mental do trabalhador e quais suas consequências na vida das pessoas? Partindo dessa indagação, este estudo tem como objetivo identificar os impactos causados pelo teletrabalho na saúde mental dos trabalhadores, apontando os principais riscos e benefícios que ele pode oferecer.

Diante deste cenário, percebe-se a importância de que as organizações adotem estratégias de apoio aos trabalhadores em teletrabalho. Tais estratégias devem contribuir para minimizar os impactos negativos do teletrabalho na saúde mental e física das pessoas, bem como a exposição a fatores de riscos psicossociais presentes no teletrabalho. Assim, esse trabalho justifica-se por cumprir um papel de alertar e conscientizar sobre os impactos do teletrabalho na vida dos trabalhadores, apontando que as organizações e a psicologia devem contribuir para a saúde deste público. Também, o estudo justifica-se pelo fato de que, apesar da crescente adoção do teletrabalho no Brasil, há poucas publicações relacionadas à saúde mental do trabalhador em teletrabalho, o que denota a importância de a Psicologia voltar seu olhar para essa nova realidade de trabalho, que tende a se intensificar no póspandemia, pesquisando sobre ela, para ter base científica e maior apropriação acerca desse fenômeno, que é próprio da sociedade contemporânea, com suas novas formas de trabalho.

Para atender ao objetivo traçado, no primeiro tópico do referencial teórico são apresentadas compreensões sobre o teletrabalho, contemplando seus aspectos históricos e conceituais, bem como o teletrabalho na pandemia; já o segundo tópico aborda os riscos e benefícios do teletrabalho; o terceiro contempla o teletrabalho e a saúde mental dos trabalhadores, trazendo também sobre a contribuição da Psicologia na saúde mental dos teletrabalhadores. Posteriormente, contempla-se o desenho metodológico da pesquisa e, por fim, as discussões e resultados, onde são apresentadas as categorizações provenientes da pesquisa nas bases de dados. As categorias de análise, as quais dão título aos tópicos da discussão, são: Impactos da Pandemia: mudanças na rotina de quem passou a atuar no teletrabalho; Vantagens e desvantagens do Teletrabalho sob diferentes perspectivas; Efeitos do teletrabalho na saúde mental e estratégias de enfrentamento dos seus riscos. 


\section{REFERENCIAL TEÓRICO}

\subsection{COMPREENSÕES SOBRE O TELETRABALHO}

Segundo a Organização Internacional do Trabalho - OIT (2007), o teletrabalho é qualquer trabalho realizado em um lugar onde, mesmo longe do estabelecimento do empregador, o trabalhador não mantém contato pessoal com seus colegas, mas comunica-se com eles através das tecnologias. Trata-se, portanto, de uma atividade laboral realizada de forma remota (à distância), utilizando para o trabalho computadores, celulares, dispositivos de comunicação e aplicativos.

Acerca dos aspectos históricos, Rocha e Amador (2018) apontam que existem registros da prática do teletrabalho desde os anos de 1950, sendo que nas décadas de 1960 e 1970 era comum a prática do trabalho em casa para a produção de vestuário, têxteis e calçados, embalagem e montagem de materiais elétricos. Porém, o teletrabalho começou a ter registros consistentes, tornando-se tema de análise acadêmica, a partir de 1990. Em consonância, o termo teletrabalho está associado ao trabalho realizado de forma remota, utilizando como meio de trabalho as tecnologias de informação e comunicação (TIC), possibilitando a obtenção dos resultados do trabalho em um local diferente daquele ocupado pela pessoa que o realiza (ROSENFIELD; ALVES, 2011).

Cabe registrar que a prática de teletrabalho ganhou mais força recentemente, devido à pandemia da COVID-19, quando, como uma forma de evitar a circulação do coronavírus, o teletrabalho, de forma compulsória, tornou-se uma necessidade, tanto para as organizações quanto para os trabalhadores.

Martins e Scalotin (2018) trazem que o mundo, de maneira geral, está vivenciando um processo de transformação no que diz respeito ao contexto social, e essa mudança tem influenciado positiva e negativamente nas atividades de diversos profissionais em teletrabalho, inclusive os profissionais que tiveram de adotar o teletrabalho de forma compulsória no período pandêmico. Nesse período, as medidas necessárias, como confinamento e quarentena de cidades inteiras, fechamento de organizações e isolamento físico, mudaram abruptamente a vida cotidiana e organizacional das pessoas (SHANAFELT; RIPP; TROCKEL, 2020).

Corroborando com o exposto, Rodrigues, Moscon, Queiroz e Silva (2020) informam que boa parte dos trabalhadores que mantiveram seus vínculos de trabalho tiveram suas rotinas alteradas de forma considerável. 0 trabalho de forma remota, que já vinha apresentando forte crescimento, precisou ser adotado rapidamente, porém, sem tempo de preparo e recursos ideais para a sua realização eficaz. Trabalhar em casa, sobretudo em contexto pandêmico, exige lidar com questões estruturais e psicológicas. Entre os teletrabalhadores, há aqueles cujas casas não comportam as demandas das organizações.

\subsection{RISCOS E BENEFICIOS DO TELETRABALHO}

Segundo Nilles (1997), uma das vantagens do teletrabalho para o trabalhador é a redução de gastos com deslocamentos e alimentação. Já Patrickson (2002) traz que um dos motivos que levam as organizações a migrarem seus funcionários ao regime do teletrabalho é a retenção de talentos, onde propiciam aos 
funcionários oportunidades de conciliar as atividades profissionais com a vida pessoal. Além disso, os profissionais que estão mais próximos da aposentadoria podem dedicar-se a outras atividades, e continuarem a contribuir com o seu conhecimento acumulado.

Um dos argumentos mais utilizados pelas empresas para que seus funcionários migrem para a modalidade do teletrabalho é a melhoria na qualidade de vida. Tremblay (2002) observa que esta é uma das vantagens percebidas pelos teletrabalhadores, principalmente, pela flexibilidade de horários, o que facilita para realizarem atividades de cunho pessoal. Tietze (2005) traz que os teletrabalhadores podem perder os limites de espaços temporais que separavam o trabalho da rotina doméstica. Como consequência, pode-se trabalhar além das horas previstas na jornada normal, passando também a disputar o espaço de casa com os membros da família.

Mann, Varey e Button (2000) levantaram alguns dos impactos percebidos por trabalhadores quanto às vantagens e desvantagens do teletrabalho. Assim, as principais vantagens seriam: menor necessidade de deslocar-se à empresa e menor custo com transporte; maior liberdade e flexibilidade de horários; melhor ambiente de trabalho; liberdade para usar roupas confortáveis; e facilidade para cumprir tarefas domésticas. Entre as principais desvantagens destacam-se: isolamento social; aumento da jornada de trabalho; falta de suporte por parte da empresa; impossibilidade de faltar por motivo de doença; dificuldade de progresso na carreira; e elevação nos custos como água, luz e internet.

Em síntese, Antunes e Fischer (2020) relatam que é possível identificar algumas situações próprias do teletrabalho, nas quais existe menor contato social, maior responsabilidade sobre a gestão do tempo, tanto nas atividades de trabalho quanto na dinâmica trabalho-família, situações essas que causam solidão, isolamento, diminuição da empatia e solidariedade, conflitos familiares, e medo de uma avaliação negativa no trabalho.

\subsection{TELETRABALHO E SAÚDE MENTAL DOS TRABALHADORES}

Não se pode duvidar das possíveis patologias psíquicas com a realização do teletrabalho, como depressão, pela junção da vida pessoal com a vida profissional, assédio psicológico, ansiedade, jornadas exaustivas, solidão, entre outros fatores (NAÇÕES UNIDAS NO BRASIL, 2017). Ainda que os teletrabalhadores afirmem que a tecnologia possibilita a comunicação síncrona através dos meios de comunicação, como celulares e computadores, a ausência da comunicação informal faz todos os envolvidos terem de despender mais tempo para solucionar um problema (KOPPMAN; GUPTA, 2014).

O Conselho Regional de Psicologia do Paraná (2020) aponta que múltiplos fatores sociais, psicológicos e biológicos podem colocar em risco o nível de saúde mental de um indivíduo como, por exemplo, as rápidas mudanças sociais, perda de laços sociais ou familiares, condições de trabalho estressantes, discriminação, exclusão social, estilo de vida não saudável, violência e violação dos direitos humanos, pressões socioeconômicas contínuas, etc. Desse modo, a mudança brusca da rotina de trabalho em razão da pandemia pode deixar consequências psicológicas 
relacionadas ao confinamento, causando danos severos à saúde psíquica do trabalhador.

Em relação ao isolamento social, Tose (2005) ressalta que esse é um fator agravante em relação ao teletrabalho, pois o homem é um ser social e seu bem-estar depende, em grande parte, das interações e vínculos criados no ambiente de trabalho. 0 teletrabalho, de forma compulsória, traz uma mudança de hábitos que gera ansiedade e, com o aumento da carga de trabalho entre os trabalhadores, há aqueles cujas residências não têm um mobiliário adequado para o desenvolvimento das atividades laborais. Essas mudanças acabam por misturar o espaço doméstico com o espaço do trabalho, tornando-se cada vez menos claro o que é tempo de trabalho e o que é tempo de lazer (ANTUNES, 2018). 0 autor traz ainda que, mesmo antes da pandemia, já era possível notar que o teletrabalho acarretava o adoecimento dos trabalhadores, por, dentre outras razões, reduzir as fronteiras entre o trabalho e a vida privada.

\section{MÉTODO}

Para Fonseca (2002), a metodologia é o ponto que direciona o caminho a ser percorrido e quais instrumentos utilizar para fundamentar uma pesquisa. Desse modo, para um melhor tratamento dos objetivos e apreciação desta pesquisa, ela é classificada como qualitativa, sendo desenvolvida por meio de uma pesquisa bibliográfica, ou seja, realizada com base em referências teóricas já estudadas e divulgadas por meios escritos e eletrônicos, como artigos científicos, livros, definindo métodos e técnicas a serem utilizadas. Complementando o exposto, de acordo com Minayo (2013), a pesquisa qualitativa coleta informações e não busca uma representação numérica, uma vez que a pesquisa com essa classificação tem como principais características as ações de observar empiricamente, descrever, compreender e explicar um determinado assunto, representando mais os significados, motivos, crenças e valores sobre o tema.

Com relação ao objetivo, o estudo é de cunho exploratório, sendo que para Gil (2018) este tipo de pesquisa proporciona uma maior familiaridade com o problema, objetivando torná-lo mais preciso. 0 autor traz ainda, que uma pesquisa exploratória é aquela usada para argumentar, modificar, ou desenvolver melhor um tema ou uma ideia, levantando hipóteses para estudos futuros. Para tanto, a pesquisa utilizou-se da revisão narrativa, que é constituída por uma análise extensa da literatura, sem estabelecer uma busca rigorosa e replicável em nível de reprodução de dados e respostas quantitativas para questões específicas, como explicitam Vosgerau e Romanowsk (2014). Os passos da revisão narrativa são definidos como: elaboração da pergunta norteadora, busca na literatura, coleta de dados, análise dos estudos encontrados, discussão dos resultados e a apresentação da revisão narrativa, que contemplará os dados encontrados de forma descritiva e comparativa (SOUZA; SILVA; CARVALHO, 2010).

Para atingir os objetivos da pesquisa, a busca bibliográfica foi realizada nas seguintes bases de dados: Scientific Electronic Library Online (SciELO), Portal de Periódicos Eletrônicos de Psicologia (PEPSIC), Literatura Latino-Americana em Ciências da Saúde (LILACS) e buscador acadêmico Google Acadêmico. Tais plataformas foram utilizadas por serem referência para pesquisas em Psicologia, 
além de possibilitarem um número maior de publicações/resultados, uma vez que o tema ainda é pouco explorado pela ciência psicológica.

Considerando o tema e o objetivo do estudo, os descritores utilizados nas buscas foram: Riscos e Benefícios do Teletrabalho; Teletrabalho e Saúde Mental; Teletrabalho e pandemia. A seleção dos materiais foi realizada conforme a seguinte ordenação: leitura dos títulos de todos os artigos encontrados nas bases de dados elencadas, sendo excluídos os que não se enquadravam no tema; leitura dos resumos dos artigos e exclusão dos que fugiam da temática pesquisada; por fim, o material selecionado foi lido na íntegra e submetido à Análise de Conteúdo. Foram adotados como critérios de inclusão: Artigos em língua portuguesa, com disponibilidade do texto nas bases de dados citadas, de forma gratuita. Os critérios de exclusão foram: trabalhos repetidos e artigos que não corresponderam ao tema da pesquisa.

0 período de coleta das informações da pesquisa foi de março de 2021 a julho de 2021. A maioria dos artigos foi publicada nos últimos dez anos, porém, também foram realizadas leituras de textos mais antigos para melhor compreender a historicidade do tema, uma vez que se trata de uma revisão narrativa. Segundo Cordeiro et al. (2007), na revisão narrativa não há critérios definidos e é possível selecionar artigos sem seguir uma sistemática, portanto, esse tipo de revisão não se preocupa em esgotar as fontes de referências.

Já a análise dos dados foi realizada por meio do método denominado "Análise de Conteúdo", o qual se trata de um método empírico que precisa ser reinventado a todo o momento, consistindo em uma técnica metodológica aplicável em discursos diversos e a todas as formas de comunicação (BARDIN, 2016). Nessa análise, o pesquisador busca compreender estruturas ou modelos que estão por trás dos fragmentos de mensagens tomadas em consideração, assim como suas características. Segundo Bardin (2016, p. 147), "as categorias são rubricas ou classes, as quais reúnem um grupo de elementos (unidades de registro, no caso de análise de conteúdo) sob um título genérico, agrupamento esse efetuado em razão das características comuns destes elementos". A autora explica que, "classificar elementos em categorias impõe a investigação do que cada um deles têm em comum uns com os outros. 0 que vai permitir o seu agrupamento é a parte comum existente entre eles" (p. 148).

A autora indica que a utilização da Análise de Conteúdo prevê três fases fundamentais, sendo elas: pré-análise, quando se realizou a leitura flutuante do material e a escolha dos artigos, formulação das hipóteses e dos objetivos; na segunda fase, realizou-se a exploração do material, e procedeu-se o recorte das unidades de registro e de contexto; e a terceira fase diz respeito à exploração do material e tratamento dos resultados, quando foram analisados os resultados brutos, tornando-os significativos e válidos.

A partir dos resultados obtidos nas bases de dados e a aplicação das etapas descritas no método da Análise de Conteúdo, chegou-se a três categorias, as quais se relacionam/atendem aos objetivos da pesquisa, sendo elas: (1) Impactos da Pandemia: mudanças na rotina de quem passou a atuar no teletrabalho; (2) Vantagens e desvantagens do Teletrabalho sob diferentes perspectivas; (3) Efeitos do teletrabalho na saúde mental e estratégias de enfrentamento dos impactos. $\mathrm{Na}$ 
sequência, serão apresentados e discutidos os resultados encontrados nas pesquisas realizadas nas bases de dados, conforme as categorias citadas.

\section{DISCUSSÃO E ANÁLISE DOS RESULTADOS}

\subsection{IMPACTOS DA PANDEMIA: MUDANÇAS NA ROTINA DE QUEM PASSOU A ATUAR NO TELETRABALHO}

Mesmo que a pandemia seja recente e que se esteja vivenciando-a no momento da escrita deste artigo, foi possível encontrar publicações sobre o tema, e diante da leitura destas, foi verificado que os principais pontos abordados pelos autores dizem respeito aos impactos do teletrabalho durante a pandemia nas relações familiares e domésticas. Desse modo, a seguir discorre-se sobre o que a literatura científica aponta sobre a pandemia e o teletrabalho, principalmente sobre os impactos referidos.

O novo coronavírus (causador da COVID-19) tem gerado impactos devastadores na saúde, economia e na rotina dos trabalhadores e das organizações (CASTRO, OLIVEIRA; MORAIS; GAI, 2020). Conforme apontado anteriormente, Rodrigues, Moscon, Queiroz e Silva (2020) relatam que grande parte dos trabalhadores que mantiveram seus vínculos empregatícios tiveram alterações consideráveis nas suas rotinas de trabalho, alterações essas que só foram possibilitadas devido ao uso das tecnologias digitais da informação e comunicação. 0 teletrabalho precisou ser adotado rapidamente, sem tempo necessário de preparo para uma realização eficaz, acarretando em grandes dificuldades e desafios, tanto para as empresas quanto para os trabalhadores.

No que tange aos trabalhadores, surgiram desafios como a necessidade de rápido aprendizado sobre as novas tecnologias, usadas para trabalho e também para auxiliar a interação entre as equipes e gestores. Para muitos teletrabalhadores, suas vidas familiares se entrelaçam com o trabalho, onde inúmeras famílias passaram a dividir em um mesmo ambiente as atividades de trabalho, educacionais, domésticas e de lazer (LOSEKANN; MOURÃO, 2020). Queiroga (2020) indica que os trabalhadores que experimentaram o teletrabalho pela primeira vez, em caráter compulsório devido à pandemia, tiveram além das demandas de aprendizagem com as novas tecnologias, que regular tempo de trabalho e tempo de descanso, encontrando equilíbrio entre o trabalho e as atividades domésticas.

Rodrigues, Moscon, Queiroz e Silva (2020) relatam que o trabalho quando exercido em casa, demanda adaptação do trabalhador em relação ao modo que irá exercer as atividades e ao seu tempo de trabalho. Os autores trazem também que a autocobrança dos trabalhadores em relação às suas atividades acaba intensificando o trabalho e, consequentemente, o aumento de horas trabalhadas diariamente. 0 trabalho remoto vem acompanhado de autonomia e flexibilidade das atividades laborais, porém, na prática, os teletrabalhadores têm um maior nível de responsabilidade com o aumento da pressão para atingir as metas e resultados esperados.

Algo a se considerar também se refere às investigações feitas sobre o teletrabalho (antes mesmo da pandemia), as quais têm demonstrado cada vez mais 
que o trabalhador que exerce o teletrabalho tende a trabalhar mais horas do que quando trabalha nas instalações da empresa. Isso se deve pelo fato do tempo que o mesmo gastaria se deslocando até o trabalho ser substituído pela realização de tarefas laborais. Há também um aumento de trabalho no período da noite, bem como aos finais de semana (OIT, 2007).

Queiroga (2020) relata que os limites entre os horários de trabalho ou lazer e as interrupções dos familiares são potenciais fontes de conflitos, além das dificuldades relacionadas à falta de mobiliário e equipamentos de informática adequados. Em alguns casos, os teletrabalhadores têm a necessidade de revezamento de dispositivos eletrônicos com familiares que também estão realizando home office ou acompanhando aulas remotas.

Araujo et al. (2021) complementam que no contexto da atual pandemia, onde os trabalhadores experimentaram o teletrabalho pela primeira vez, sem preparo e treinamento prévio, muitos têm se deparado com sentimento de angústia, ansiedade e insegurança. Pérez-Nebra, Carlotto e Sticca (2020) contribuem expondo que quando se trata de um cenário de pandemia, o acúmulo de atividades, sejam domésticas ou de trabalho, implica em desgaste físico e psicológico sem precedentes.

\subsection{VANTAGENS E DESVANTAGENS DO TELETRABALHO SOB DIFERENTES PERSPECTIVAS}

O teletrabalho pode apresentar impactos tanto positivos quanto negativos nas organizações, na vida dos trabalhadores e, consequentemente, na sociedade. Desta forma, cabe apresentar os dados encontrados na literatura referentes às vantagens e desvantagens do teletrabalho, sob as perspectivas organizacional, individual e social.

Em termos de vantagens organizacionais do teletrabalho, observa-se que existe aumento na produtividade, onde os sujeitos podem trabalhar em períodos que considerem mais proveitosos e de maior satisfação, o que gera, por conseguinte, menor rotatividade de colaboradores nas organizações. Além disso, há redução de custos com materiais de escritório, eletricidade, estacionamento, dentre outros. 0 processo de recrutamento e seleção também torna-se mais eficiente, visto que ocorre a inserção de trabalhadores de territórios mais distantes, facilitando, assim, a contratação de indivíduos que, de outra forma, não poderiam fazer parte do grupo de funcionários da empresa, o que possibilita manter as atividades, mesmo em períodos de catástrofes naturais, epidemias ou pandemias (FERREIRA JÚNIOR, 2000; NILLES 1997; GOULART, 2009).

Quanto ao nível individual, Kugelmass (1996) traz que o teletrabalhador experiencia algumas vantagens, onde tem redução de custos com o deslocamento, economia de tempo e redução do desgaste físico e psicológico decorrentes da locomoção. Além disso, há maior liberdade na gestão do horário de trabalho, local onde irá trabalhar, maior nível de concentração, e menos interrupções, comparando com o escritório, o que gera maior autonomia nas atividades desenvolvidas.

Para Mello et al. (2014) e Goulart (2009), o teletrabalho contribui também para algumas vantagens sociais, tais como: a diminuição dos níveis de 
poluição, em decorrência da redução do deslocamento dos teletrabalhadores ao trabalho; atenua a exclusão social, pois idosos e pessoas com deficiência (PCD), que podem apresentar dificuldades em sair de casa para trabalhar, podem integrar equipes de teletrabalho. Boonen (2003) aponta ainda como benefício social do teletrabalho a redução de custos relacionados à infraestrutura das cidades e a diminuição de acidentes de trânsito.

Entretanto, existem também algumas desvantagens acerca do teletrabalho. No que concerne às desvantagens organizacionais, Silva et al. (1998) elenca a dificuldade de supervisionar e avaliar o desempenho dos teletrabalhadores. Além das desvantagens experienciadas pelas empresas, existem também desafios provocados pelo teletrabalho, tais como: criar um novo estilo de gerenciamento e formação de equipes, sem a interação física. Cabe, pois, moldar um novo ambiente de trabalho, sem escritório, onde o trabalhador seja automotivado para desenvolver sua carreira e disciplinado para produzir isoladamente. Ainda, deve-se atentar para mudanças nos laços familiares e comunitários em razão da flexibilidade de local e horários advindos da utilização do teletrabalho (LIMA; FUSCO; RIÇA, 2003).

Já como desvantagem em termos pessoais da modalidade do teletrabalho, Antunes e Fischer (2020) apontam a intensificação do trabalho, que pode levar a uma extensa carga horária; dificuldade na comunicação com chefias e colegas; intromissões na vida privada, as quais levam algumas vezes a conflitos trabalhofamília; aumento da ansiedade e do estresse, podendo gerar sintomas psicossomáticos, como dores de cabeça e nas costas; aumento do isolamento social e profissional, devido à falta de contato presencial com chefias e colegas; e também uma menor visibilidade para futuras promoções profissionais, visto que o contato com superiores diminui. Complementando:

O descontrole do gerenciamento da vida doméstica, aliado ao excesso de trabalho, pode gerar um vício comportamental - o indivíduo está sempre contactável e sob pressão profissional para realizar determinada tarefa, sempre tendendo a prolongar o tempo diário de trabalho (SOUZA 2005, p. 18).

Tietze (2005) traz que os teletrabalhadores acabam trabalhando além das horas previstas em sua carga horária de trabalho, passando a disputar o espaço da casa com seus familiares, pois perdem o limite de espaços temporais que separavam o trabalho da rotina doméstica. Para Costa (2007), cabe o entendimento de que o lar e o trabalho são mundos culturalmente distintos e que, misturando-os, conflitos poderão ocorrer.

Também, segundo Boonen (2003), alguns teletrabalhadores não dispõem de um ambiente propício para realização do teletrabalho. Barulhos como os de crianças, animais, rádio ou televisão podem ser motivos de dispersão do teletrabalhador das suas atividades, causando interrupções. Souza (2005) complementa que misturar a vida profissional com a vida doméstica pode ocasionar um caos. Ou seja, a família pode intervir de modo negativo na vida profissional do teletrabalhador na medida em que assuntos domésticos podem distrair o indivíduo, causando lentidão na realização das tarefas ou até mesmo erros na execução das mesmas. Com isso, Nilles (1997) traz que, às vezes, é necessária uma negociação 
com familiares, onde seja delimitado o espaço de trabalho, evitando, assim, certas interrupções.

Já com relação às desvantagens sociais, Antunes e Fischer (2020) apontam como aspecto negativo para a sociedade $o$ isolamento vivido pelos teletrabalhadores, uma vez que diminui a interação e o contato dos indivíduos. Ademais, dentro das desvantagens do teletrabalho, encontram-se os impactos causados na saúde mental do trabalhador. Castro, Oliveira, Morais e Gai (2020) sinalizam que esta modalidade de trabalho demanda atentar para aspectos relacionados à saúde mental dos trabalhadores, uma vez que ocasiona rompimento de contato físico com outras pessoas, contato este ao qual os trabalhadores estavam habituados. Neste cenário, são necessárias estratégias de enfrentamento dos impactos à saúde mental dos teletrabalhadores, aspectos estes que serão discutidos a seguir.

\subsection{EFEITOS DO TELETRABALHO NA SAÚDE MENTAL E ESTRATÉGIAS DE ENFRENTAMENTO DOS SEUS RISCOS}

0 primeiro ponto a se destacar neste tópico é que pesquisas relacionadas ao teletrabalho e a saúde mental ainda são escassas. Isso é confirmado por Fonseca e Perez-Nebra (2012), autores que referem que o teletrabalho tem sido abordado em estudos, principalmente pelas teorias da administração. Já na Psicologia, os fenômenos relacionados à saúde mental ainda são pouco explorados, uma vez que são encontradas poucas pesquisas sobre o tema. Como visto anteriormente, o teletrabalho pode causar impactos (riscos) diversos aos teletrabalhadores, acarretando, por exemplo, o desenvolvimento de estresse, comprometendo a saúde mental do indivíduo. Logo, é fundamental o desenvolvimento de pesquisas que subsidiem ações, especialmente para que as organizações adotem estratégias de enfrentamento que minimizem os efeitos prejudiciais do teletrabalho na saúde mental dos teletrabalhadores.

Malvezzi (2004) salienta que o trabalho tem muita influência na vida das pessoas, apresentando papel ativo na vida em sociedade e na construção da identidade dos sujeitos. Além disso, conforme Codo, Soratto e Vasques-Menezes (2004), o trabalho ajuda a compreender o ser humano como um todo e não pode ser desassociado do leque das múltiplas determinações da saúde mental. Cabe salientar também que, em determinadas situações, a tensão causada pelo trabalho é produtora de sofrimento psíquico, especialmente no choque entre a história pessoal do sujeito, seus projetos, esperanças e desejos, com uma organização laboral que os ignora (DEJOURS, 1999).

Losekann e Mourão (2020) apontam algumas reações comportamentais que podem causar danos à saúde mental dos teletrabalhadores, como a perda de apetite e sono, alterações de humor, causadas pelos conflitos interpessoais, letargia ou agitação, crises de pânico, causadas pelo aumento da ansiedade, dentre outras. É possível observar também alguns transtornos psíquicos, como a depressão. Os autores referem também que a percepção de como está a saúde mental dos teletrabalhadores se torna um grande desafio no trabalho à distância. Diante disso, torna-se imprescindível que a gestão de pessoas das organizações estabeleça boas 
práticas de comunicação e interação entre os membros da equipe, a fim de compreender e intervir nos efeitos nocivos do teletrabalho na saúde das pessoas.

Quanto ao teletrabalho no contexto pandêmico, há que se considerar o medo, receio, incertezas, sentimento de solidão, perdas, luto e estresse causados pela pandemia. Esses estados afetivos somaram-se aos desafios de aprendizagem dos trabalhadores que migraram para o teletrabalho sem treinamento adequado (ABBAD; LEGENTIL, 2020). Complementando o exposto, Silva (2019) refere que, apesar de todos os recursos modernos de comunicação, a falta de contato físico com colegas de trabalho em decorrência do isolamento social também incorre em efeitos à saúde mental dos teletrabalhadores, pois pode afetar psicologicamente este trabalhador, gerando sentimento de insegurança. Nesse contexto, o autor aponta que cabe aos profissionais da área de gestão de pessoas buscarem estratégias para evitar que o teletrabalho seja um fator de estresse, adoecimento, burnout ou ansiedade. Para evitar sentimentos e resultados indesejáveis, pode-se incentivar que o teletrabalho mantenha características positivas como autonomia, variedade e identidade das tarefas, suporte social, feedbacks construtivos de outras pessoas, contexto de trabalho confortável e ergonomicamente adequado à sua realização.

Já no que concerne à relação trabalho-família no mesmo espaço, segundo Antunes (2018), quando ocorre tal junção, conflitos poderão ocorrer. Costa (2003) indica que, diante de conflitos dessa ordem, é necessário que o teletrabalhador e seus familiares redefinam as fronteiras do trabalho, para assim poder transformar a convivência familiar a partir desse novo contexto. Entretanto, a relação do homem consigo mesmo também pode apresentar variações e conflitos, impactando sua saúde mental. Aspectos como comprometimento, motivação e carga mental, refletem no desenvolvimento e nas relações do teletrabalhador frente ao trabalho. Assim, quando o trabalhador está em sofrimento psíquico, ocorre a queda do seu comprometimento. Em contraponto, quando não há sofrimento, os níveis de comprometimento são maiores, reduzindo assim a incidência de psicopatologias, principalmente a depressão (CODO, 2003).

Diante do exposto, percebe-se a necessidade de um olhar atento à saúde mental dos teletrabalhadores. E segundo Castro, Oliveira, Morais e Gai (2020), cabe às organizações adotarem medidas de apoio e bem-estar a estes trabalhadores, sendo que dentre as possíveis estratégias de apoio e intervenções para minimizar os impactos negativos e promover a saúde mental dos trabalhadores estão, por exemplo, a criação de canais de acolhimento psicológico e a efetiva comunicação corporativa. Os autores trazem ainda sobre a importância do fornecimento de recursos e suporte para a execução do teletrabalho, assim como o auxílio na organização do tempo do teletrabalhador.

\section{CONCLUSÃO}

Ao finalizar este estudo, pode-se perceber que, embora o teletrabalho seja uma modalidade de trabalho utilizada a algumas décadas, existem poucos estudos no Brasil que abordam os impactos do teletrabalho na saúde mental dos teletrabalhadores, sendo que grande parte dos estudos encontrados para a construção deste trabalho são da área da administração e não enfocam a saúde deste trabalhador. Mesmo com pouca literatura sobre o tema, o que considera-se a 
principal limitação desta pesquisa, foi possível perceber que o teletrabalho abarca aspectos positivos, dentre eles, o ganho de tempo do teletrabalhador, por não precisar se deslocar até a empresa, todavia, os pontos negativos se destacam, sendo que o teletrabalho pode causar danos à saúde mental dos trabalhadores. Dentre esses danos encontram-se alterações no sono e no humor, causadas pelos conflitos interpessoais, transtornos de ansiedade, depressão, entre outros.

Já com relação aos trabalhadores que passaram a utilizar o teletrabalho no período pandêmico, compreendeu-se que estes enfrentaram alterações significativas nas suas rotinas, uma vez que as demandas de trabalho, afazeres domésticos, família e lazer, deixaram menos claros os limites entre o tempo de trabalho e de vida pessoal. Há também, as dificuldades enfrentadas pelos teletrabalhadores que não possuem materiais adequados para a realização das atividades, como mesa e cadeira. Porém, pode-se constatar que os trabalhadores que tiveram a possibilidade de migrar para o teletrabalho, mesmo que sem preparo, tiveram a preservação de seu emprego e suas rendas, uma vez que essa foi uma das medidas tomadas a fim de resguardar a saúde dos trabalhadores, assim como diminuir a proliferação do vírus.

Devido à importância do tema, sugere-se que novas pesquisas a respeito da saúde mental dos trabalhadores que exercem o teletrabalho sejam realizadas, especialmente através de pesquisas empíricas, visto que esse é um assunto que requer atenção e cuidado, sendo, inclusive, assunto de interesse da saúde pública. Como a pandemia tornou o teletrabalho uma realidade, acredita-se que, em muitos casos, ele não será mais uma alternativa ao momento de isolamento, mas a forma de trabalho prioritária em muitas organizações.

Recomenda-se, assim, que as organizações atentem para manifestações diversas, como alterações comportamentais (desinteresse/desmotivação, falta de atenção) e baixa produtividade/rendimento, as quais poderão indicar que a saúde mental do trabalhador foi impactada. Identificar esses efeitos é a primeira etapa para que os gestores pensem formas de intervir evitando o adoecimento dos teletrabalhadores. Há que se compreender que mesmo em trabalho remoto, deve-se acompanhar os trabalhadores, adaptando ferramentas clássicas da gestão de pessoas ou criando novos métodos para escutar e orientar os sujeitos, para que estes não se sintam desamparados. Em suma, sugere-se que as empresas/instituições voltem seu olhar ao teletrabalho e, consequentemente, proponham ações que contribuam com a saúde mental dos teletrabalhadores.

\section{REFERÊNCIAS}

ABBAD, G. S.; LEGENTIL, J. Novas Demandas de Aprendizagem dos Trabalhadores Face à Pandemia da COVID-19. In: MORAES, M. M. (org.). Os impactos da pandemia para o trabalhador e suas relações com o trabalho. Porto Alegre: Artmed, 2020. p. 45-57. (Coleção 0 trabalho e as medidas de contenção da COVID-19: contribuições da Psicologia Organizacional e do Trabalho no contexto da pandemia, v. 2). Disponível em: https://www.sbpot.org.br/publicacao/volume-2-os-impactos-dapandemia-para-o-trabalhadore-suas-relacoes-com-o-trabalho/. Acesso em: 11 jun. 2021.

ANTUNES, E. D.; FISCHER, F. M. Ninguém é uma ilha: os riscos do teletrabalho à saúde do trabalhador e da trabalhadora. Associação Paulista de Medicina do Trabalho (APMT), São Paulo, ago. 2020. (Série temática, teletrabalho). Disponível em: https://apmtsp.org.br/aspectos-adversosdo-teletrabalho-para-a-saude-dos-trabalhadores/. Acesso em: 22 nov. 2020. 
ANTUNES, R. 0 privilégio da servidão: um novo proletariado de serviços na era digital. 1. ed. São Paulo: Boitempo, 2018.

ARAUJO, S. E. A. et al. Impacto da COVID-19 sobre o atendimento de pacientes oncológicos: experiência de um centro oncológico localizado em um epicentro Latino-Americano da pandemia. Einstein, São Paulo, v. 19, 2021. Disponível em: https://doi.org/10.31744/einstein_journal/2021A06282. Acesso em: 11 jun. 2021.

BARDIN, L. Análise de conteúdo. São Paulo: Edições 70, 2016.

BOONEN, E. M. As várias faces do teletrabalho. Revista Economia e Gestão, Belo Horizonte, v. 2-3, n. 4-5, p. 106-127, dez. 2002/jul. 2003. Disponível em:

http://periodicos.pucminas.br/index.php/economiaegestao/article/view/104. Acesso em: 03 maio 2021.

CASTRO, B. L. G.; OLIVEIRA, J. B. B.; MORAIS, L. Q.; GAI, M. J. P. COVID-19 e organizações: estratégias de enfrentamento para redução de impactos. Revista Psicologia Organizações e Trabalho, Brasília, v. 20, n. 3, p. 1059-1063, set. 2020. Disponível em: http://dx.doi.org/10.17652/rpot/2020.3.20821. Acesso em: 05 jun. 2021.

CODO, W. Um diagnóstico do trabalho com ênfase em saúde mental. In: JACQUES, M. G.; CODO, W. (org.). Saúde Mental \& Trabalho: leituras. 2. ed. Petrópolis: Vozes, 2003. p. 173-190.

CODO, W.; SORATTO, L.; VASQUES-MENEZES, I. Saúde mental e trabalho. In: ZANELLI, J. C.; BORGES-ANDRADE, J. E.; BASTOS, A. V. B. (org.). Psicologia, organizações e trabalho no Brasil. Porto Alegre: Artmed. 2004. p. 276-299.

CONSELHO REGIONAL DE PSICOLOGIA DO PARANÁ. 0 sofrimento psíquico das (os) trabalhadoras (es) em tempos de Pandemia. Paraná, maio 2020. Disponível em: https://crppr.org.br/1demaio/. Acesso em: 12 set. 2020.

CORDEIRO, A. M. et al. Revisão sistemática: uma revisão narrativa. Revista do Colégio Brasileiro de Cirurgiões, Rio de Janeiro, v. 34, n. 6, p. 428-431, 2007. Disponível em: https://doi.org/10.1590/S0100-69912007000600012. Acesso em: 05 jun. 2021.

COSTA, I. S. A. Poder/saber e subjetividade na construção do sentido do teletrabalho. 2003. Tese (Doutorado em Administração) - Fundação Getúlio Vargas, Rio de Janeiro, 2003. Disponível em: https://bit.ly/2UIDP7H. Acesso em: 15 jun. 2021.

COSTA, I. S. A. Teletrabalho: subjugação e construção de subjetividades. Revista de Administração Pública, Rio de Janeiro, v. 41, n. 1, p. 105-124, jan./fev. 2007. Disponível em: https://doi.org/10.1590/S0034-76122007000100007. Acesso em: 12 jun. 2021.

DEJOURS, C. Psychologie clinique du travail et tradition compréhensive. In: CLOT, Y. (dir.). Les histoires de la psychologie du travail: approche pluridisciplinaire. 2. ed. Toulouse: Octarès, 1999. p. 195-219.

FERREIRA JÚNIOR, J. C. Telecommuting: o paradigma de um novo estilo de trabalho. Revista Administração de Empresas, São Paulo, v. 7, n. 3, p. 8-17, jul./set. 2000. Disponível em: https://doi.org/10.1590/S0034-75902000000300012. Acesso em: 02 maio 2021.

FONSECA, J. J. S. Metodologia da pesquisa científica. Fortaleza: UEC, 2002.

FONSECA, R. L. A.; PEREZ-NEBRA, A. R. A epidemiologia do teletrabalhador: impactos do teletrabalho na saúde mental. Cadernos de Psicologia Social do Trabalho, São Paulo, v. 15, n. 2, p. 303-318, dez. 2012. Disponível em:

http://pepsic.bvsalud.org/scielo.php?script=sci_arttext\&pid=S1516-

$37172012000200011 \& \operatorname{lng}=$ pt\&nrm=iso. Acesso em: 22 nov. 2020.

GIL, A. C. Como elaborar projetos de pesquisa. 4. ed. São Paulo: Atlas, 2018. 
GOULART, J. Teletrabalho: alternativa de trabalho flexível. Brasília: Senac, 2009.

KOPPMAN, S.; GUPTA, A. Navigating the mutual knowledge problem: a comparative case study of distributed work. Information Technology and People, v. 27, n. 1, p. 83-105, 2014. Disponível em: https://doi.org/10.1108/ITP-12-2012-0153. Acesso em: 23 dez. 2020.

KUGELMASS, J. Teletrabalho: novas oportunidades para o trabalho flexível. São Paulo: Atlas, 1996.

LIMA, F. U.; FUSCO, J. P. A; RIÇA, R. A tecnologia transforma o teletrabalho domiciliar em diferencial de competitividade. In: ENCONTRO NACIONAL DE ENGENHARIA DE PRODUÇÃO, 23., Ouro Preto, 2003. Disponível em: http://www.abepro.org.br/biblioteca/enegep2003_tr0113_0760.pdf. Acesso em: 04 maio 2021.

LOSEKANN, R. G. C. B.; MOURÃO, H. C. Desafios do teletrabalho na pandemia COVID19: quando o home vira office. Caderno de Administração, Maringá, v. 28, ed. esp., p. 71- 75, jun. 2020. Disponível em: https://periodicos.uem.br/ojs/index.php/CadAdm/article/view/53637/751375150139. Acesso em: 07 jun. 2021.

MALVEZZI, S. Prefácio. In: ZANELLI, J. C.; BORGES-ANDRADE, J. E.; BASTOS, A. V. B. (org.). Psicologia, organizações e trabalho no Brasil. Porto Alegre: Artmed, 2004. p. 13- 17.

MANN, S.; VAREY, R.; BUTTON, W. An exploration of the emotional impact of teleworking via computer-mediated communication. Journal of Managerial Psychology, v. 15, n. 7, p. 668-690, 2000. Disponível em: https://doi.org/10.1108/02683940010378054. Acesso em: 23 jan. 2020.

MARTINS, L. A.; SCATOLIN, H. G. O papel do psicólogo no ambiente de trabalho na prevenção das doenças ocupacionais dos profissionais da educação. Revista ESPACIOS, v. 39, n. 43, p. 14-26, 2018 Disponível em: http://www.revistaespacios.com/a18v39n43/a18v39n43p14.pdf. Acesso em: 06 dez. 2020.

MELLO, A. et al. Teletrabalho Como Fator de Inclusão Social e Digital em Empresas de Call Center/Contact Center. Revista de Administração da UFSM, Santa Maria, v. 7, n. 3, 2014.

MELLO, A. Teletrabalho (telework) o trabalho em qualquer lugar e a qualquer hora. Rio de Janeiro: Qualitymark, 1999.

MINAYO, M. C. S. 0 desafio do conhecimento: pesquisa qualitativa em saúde. 13. ed. São Paulo: Hucitec, 2013.

NAÇÕES UNIDAS NO BRASIL. OMS: empresas devem promover saúde mental de funcionários no ambiente de trabalho. Brasília, 2017. Disponível em: https://brasil.un.org/pt-br/77852-omsempresas-devem-promover-saude-mental-de-funcionarios-no-ambiente-trabalho. Acesso em: 15 dez. 2020.

NILLES, J. M. Fazendo do teletrabalho uma realidade: um guia para telegerentes e teletrabalhadores. São Paulo: Futura, 1997.

ORGANIZAÇÃO INTERNACIONAL DO TRABALHO. Declaração da OIT sobre os princípios e direitos fundamentais no trabalho e seu seguimento: adotada durante a Conferência Internacional do Trabalho na octogésima sexta reunião, Genebra, 18 de junho de 1998. Brasília: OIT, 2007.

PATRICKSON, M. Teleworking: potential employment opportunities for older workers?

International Journal of Manpower, v. 23, n. 8, p. 704 - 715, 2002. Disponível em: https://www.emerald.com/insight/content/doi/10.1108/01437720210453902/full/html. Acesso em: 05 jan. 2021.

PÉREZ-NEBRA, A. R.; CARLOTTO, M. S.; STICCA, M. G. Bem-estar e estresse ocupacional em contexto de distanciamento social. In: QUEIROGA, F. (org.). Orientações para o home office durante a pandemia da COVID-19. Porto Alegre: Artmed, 2020. p. 31-37. (Coleção 0 trabalho e as medidas de contenção da COVID-19: contribuições da Psicologia Organizacional e do Trabalho no contexto da 
pandemia, v. 1). Disponível em: https://www.sbpot.org.br/publicacao/volume-1-home-officeguidelines-in-the-covid-19-pandemic-2/. Acesso em: 21 mar. 2021.

QUEIROGA, F. (org.). Orientações para o home office durante a pandemia da COVID-19. Porto Alegre: Artmed, 2020. p. 31-37. (Coleção 0 trabalho e as medidas de contenção da COVID-19: contribuições da Psicologia Organizacional e do Trabalho no contexto da pandemia, v. 1). Disponível em: https://www.sbpot.org.br/publicacao/volume-1-home-office-guidelines-in-thecovid-19-pandemic-2/. Acesso em: 11 mar. 2021.

ROCHA, C. T. M.; AMADOR, F. S. 0 teletrabalho: conceituação e questões para análise. Cadernos EBAPE.BR, Rio de Janeiro, v. 16, n. 1, p. 152-162, jan. 2018. Disponível em: http://dx.doi.org/10.1590/1679-395154516. Acesso em: 21 nov. 2020.

RODRIGUES, A. C. A.; MOSCON, D. C. B.; QUEIROZ, G. C.; SILVA, J. C. Trabalhadores na pandemia: múltiplas realidades, múltiplos vínculos. In: MORAES, M. M. (org.). Os impactos da pandemia para o trabalhador e suas relações com o trabalho. Porto Alegre: Artmed, 2020. p. 1-14. (Coleção 0 trabalho e as medidas de contenção da COVID-19: contribuições da Psicologia Organizacional e do Trabalho no contexto da pandemia, v. 2). Disponível em:

https://www.sbpot.org.br/publicacao/volume-2-os-impactos-da-pandemia- para-o-trabalhador-esuas-relacoes-com-o-trabalho/. Acesso em: 11 jun. 2021.

ROSENFIELD, C. L.; ALVES, D. A. Teletrabalho. In: CATTANI, A. D.; HOLZMANN, L. (org.). Dicionário de trabalho e tecnologia. Porto Alegre: Zouk, 2011. p. 414-418.

SARDESHMUKH, S. R.; SHARMA, D.; GOLDEN, T. D. Impact of telework on exhaustion and job engagement: a job demands and job resources model. New Technology, Work and Employment, $\mathrm{v}$. 27, n. 3, p. 193-207, 2012. Disponível em: https://doi.org/10.1111/j.1468-005X.2012.00284.X. Acesso em: 31 dez. 2020.

SCHMIDT, B. et al. Saúde mental e intervenções psicológicas diante da pandemia do novo coronavírus (COVID-19). Estudos de Psicologia, Campinas, v. 37, p. 2-13, 2020. Disponível em: https://doi.org/10.1590/1982-0275202037e200063. Acesso em: 13 dez. 2020.

SHANAFELT, T.; RIPP, J.; TROCKEL, M. Understanding and addressing sources of anxiety among health care professionals during the COVID-19 pandemic. Journal of The American Medical Association, v. 323, n. 21, p. 2133-2134, 2020. Disponível em: https://jamanetwork.com/journals/jama/fullarticle/2764380. Acesso em: 31 dez. 2020.

\section{SILVA, A. et al. Estudo do teletrabalho em Portugal. Lisboa: FUNDETEC, 1998.}

SILVA, O. A. A reforma trabalhista e o teletrabalho em domicílio: saúde e qualidade de vida. 2019. Trabalho de Conclusão de Curso (Graduação em Direito) - Universidade Federal do Rio Grande do Sul, Porto Alegre, 2019. Disponível em:

https://www.lume.ufrgs.br/bitstream/handle/10183/199908/001100824.pdf?sequence=1\&isAl lowed=y. Acesso em: 14 jun. 2021

SOUZA, M. R. S. Habitação e informatização: o teletrabalho. 2005. Dissertação (Pós-Graduação em Arquitetura) - Universidade de São Paulo, São Carlos, 2005. Disponível em:

http://www.nomads.usp.br/documentos/textos/cultura_digital/mono_MarceloSouza.pdf. Acesso em: 07 maio 2021

SOUZA, M. T.; SILVA, M. D.; CARVALHO, R. Revisão integrativa: o que é e como fazer. Einstein, Morumbi, v. 8, n. 1, p. 102-106, 2010. Disponível em: http://pt.scribd.com/doc/56528038/A2Revisao-integrativa-o-que-e-e-como-fazer. Acesso em: 15 maio 2021.

TIETZE, S. Discourse as strategic coping resource: managing the interface between "home" and "work". Journal of Organizational Change Management, v. 18, n. 1, p. 48-62, 2005. Disponível em: https://doi.org/10.1108/09534810510579841. Acesso em 30 dez. 2020. 
TOSE, M. G. L. S. Teletrabalho: a prática do trabalho e a organização subjetiva dos seus agentes. 2005. Tese (Doutorado em Ciências Sociais) - Pontifícia Universidade Católica de São Paulo, São Paulo, 2005. Disponível em: https://tede2.pucsp.br/handle/handle/3507. Acesso em: 31 dez. 2020.

TREMBLAY, D. Balancing work and family with telework? Organizational issues and challenges for women and managers. Women in Management Review, v.17, n. 3-4, p. 157-170, 2002. Disponível em: https://doi.org/10.1108/09649420210425309. Acesso em: 25 set. 2020.

VOSGERAU, D. S. R.; ROMANOWSKI, J. P. Estudos de revisão: implicações conceituais e metodológicas. Revista de Diálogo Educacional, Paraná, v. 14, n. 1, p. 165-189, 2014. Disponível em: http://dx.doi.org/10.7213/dialogo.educ.14.041.DS08. Acesso em: 7 mar. 2021. 